PPPL-3455

PPPL-3455

UC-70

Diagnostics for Liquid Lithium Experiments in CDX-U

by

R. Kaita, P. Efthimion, D. Hoffman, B. Jones, H. Kugel, R. Majeski,

T. Munsat, S. Raftopoulos, G. Taylor, J. Timberlake, V. Soukhanovskii,

D. Stutman, M. lovea, M. Finkenthal, R. Doerner,

S. Luckhardt, R. Maingi, and R. Causey

June 2000

$\int \frac{D}{5}[\sqrt{\zeta}] \int \Omega \begin{aligned} & \text { PAINCETON } \\ & \text { PLABMA PHYSICS } \\ & \text { LABOAATOAY }\end{aligned}$

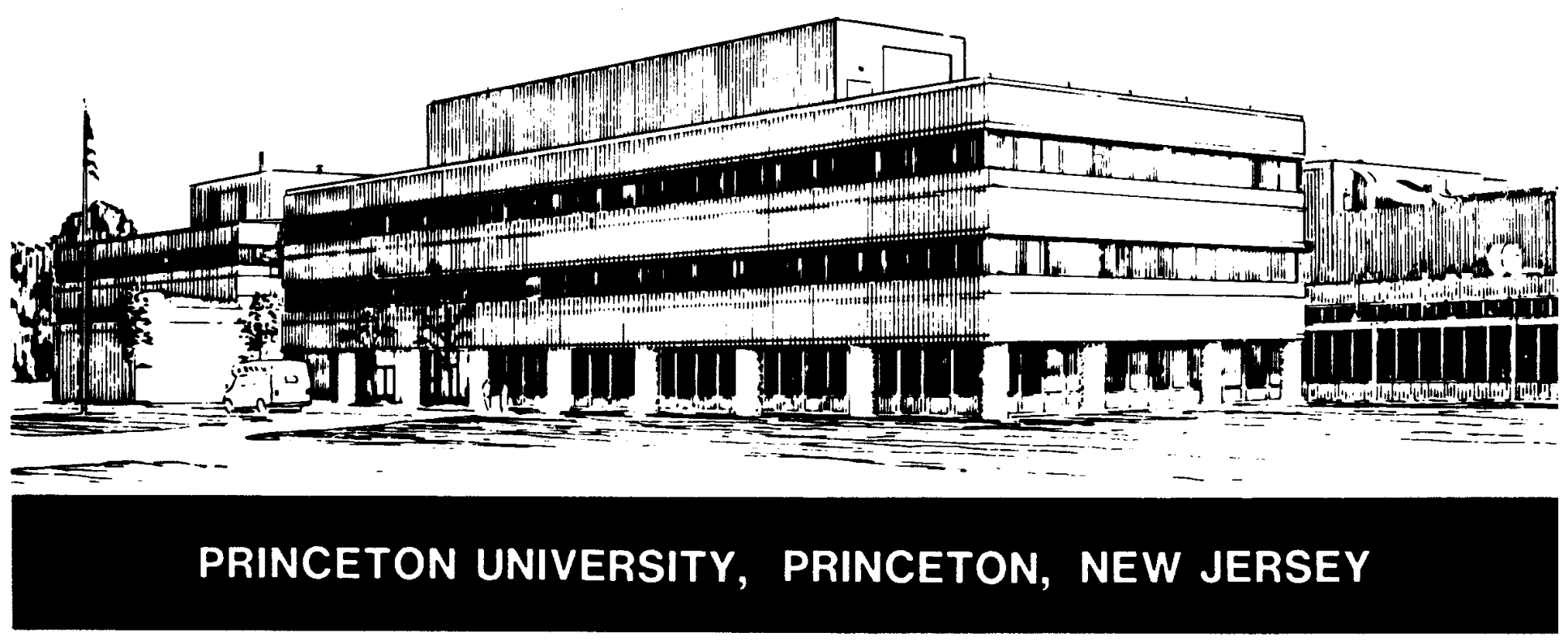




\section{PPPL Reports Disclaimer}

This report was prepared as an account of work sponsored by an agency of the United States Government. Neither the United States Government nor any agency thereof, nor any of their employees, makes any warranty, express or implied, or assumes any legal liability or responsibility for the accuracy, completeness, or usefulness of any information, apparatus, product, or process disclosed, or represents that its use would not infringe privately owned rights. Reference herein to any specific commercial product, process, or service by trade name, trademark, manufacturer, or otherwise, does not necessarily constitute or imply its endorsement, recommendation, or favoring by the United States Government or any agency thereof. The views and opinions of authors expressed herein do not necessarily state or reflect those of the United States Government or any agency thereof.

\section{Availability}

This report is posted on the U.S. Department of Energy's Princeton Plasma Physics Laboratory Publications and Reports web site in Calendar Year 2000. The home page for PPPL Reports and Publications is: http://www.pppl.gov/pub_report/

DOE and DOE Contractors can obtain copies of this report from:

U.S. Department of Energy

Office of Scientific and Technical Information

DOE Technical Information Services (DTIS)

P.O. Box 62

Oak Ridge, TN 37831

Telephone: (865) 576-8401

Fax: (865) 576-5728

Email: reports@adonis.osti.gov

This report is available to the general public from:

National Technical Information Service

U.S. Department of Commerce

5285 Port Royal Road

Springfield, VA 22161

Telephone: $1-800-553-6847$ or

(703) $605-6000$

Fax: (703) 321-8547

Internet: http://www.ntis.gov/ordering.htm 


\title{
Diagnostics for Liquid Lithium Experiments in CDX-U
}

\author{
R. Kaita, ${ }^{\mathrm{a}}$ P. Efthimion, ${ }^{\mathrm{a}}$ D. Hoffman, ${ }^{\mathrm{b}}$ B. Jones, ${ }^{\mathrm{a}}$ H. Kugel, ${ }^{\mathrm{a}}$ \\ R. Majeski, ${ }^{\mathrm{a}}$ T. Munsat, ${ }^{\mathrm{a}}$ S. Raftopoulos, ${ }^{\mathrm{a}} \mathrm{G}$. Taylor, ${ }^{\mathrm{a}}$ \\ J. Timberlake, ${ }^{a}$ V. Soukhanovskii, ${ }^{c}$ D. Stutman, ${ }^{c}$ M. Iovea, ${ }^{c}$ \\ M. Finkenthal, ${ }^{\mathrm{c}}$ R. Doerner, ${ }^{\mathrm{d}}$ S. Luckhardt, ${ }^{\mathrm{d}}$ R. Maingi, ${ }^{\mathrm{e}}$ R. Causey ${ }^{\mathrm{f}}$ \\ ${ }^{a}$ Princeton Plasma Physics Laboratory, ${ }^{b}$ Drexel University, \\ ${ }^{\mathrm{c}}$ Johns Hopkins University, ${ }^{\mathrm{d}}$ University of California at San Diego, ${ }^{\mathrm{e}}$ Oak Ridge National \\ Laboratory, ${ }^{\mathrm{e}}$ Sandia National Laboratories
}

\begin{abstract}
A flowing liquid lithium first wall or divertor target could virtually eliminate the concerns with power density and erosion, tritium retention, and cooling associated with solid walls in fusion reactors. To investigate the interaction of a spherical torus plasma with liquid lithium limiters, large area divertor targets, and walls, discharges will be established in the Current Drive Experiment-Upgrade (CDX-U) where the plasma-wall interactions are dominated by liquid lithium surfaces. Among the unique CDX-U lithium diagnostics is a multi-layer mirror (MLM) array, which will monitor the $135 \AA$ LiIII line for core lithium concentrations. Additional spectroscopic diagnostics include a grazing incidence XUV spectrometer (STRS) and a filterscope system to monitor $D_{\alpha}$ and various impurity lines local to the lithium limiter. Profile data will be obtained with a multichannel tangential bolometer and a multipoint Thomson scattering system configured to give enhanced edge resolution. Coupons on the inner wall of the CDX-U vacuum vessel will be used for surface analysis. A 10,000 frame per second fast visible camera and an IR camera will also be available.
\end{abstract}

\section{Introduction}

Recent reactor studies ${ }^{1}$ have identified liquid walls as a potentially "revolutionary" solution of generic MFE first-wall problems, such as heat load and erosion limits of dry walls, neutron damage and activation, reliability/maintainability of first walls, and tritium inventory and breeding. A liquid metal wall in close proximity to the last closed flux surface may significantly 
enhance stability and performance, by providing a surface that has low or no recycling. The benefits of such conditions have already been demonstrated during the DOLLOP lithium wall conditioning experiments, ${ }^{2}$ for example, in TFTR.

Lithium offers an attractive synthesis of desirable liquid metal wall properties, but implementation of a liquid metal divertor or wall in large fusion devices requires tests on a smaller scale device. A first test of liquid metals at the NSTX scale is not likely, even though spherical tori (ST's) have an acute need for high heat load divertor and wall systems. As a necessary step, the CDX-U program has now been wholly dedicated to the testing of liquid metal limiter, divertor and wall concepts. ${ }^{3} \mathrm{~A}$ major feature of CDX-U which makes this practical is its diagnostic set, which is well-suited to liquid lithium experiments. These systems are described in this paper.

\section{Description of the CDX-U Facility}

The Current Drive Experiment-Upgrade (CDX-U) is a spherical torus facility ${ }^{4}$ that has recently undergone an extensive program of upgrades which has resulted in an increase of the toroidal field to $2.3 \mathrm{kG}$. The new power supplies for the toroidal, vertical, and shaping fields (with the exception of the capacitor banks for the Ohmic heating solenoid) are preprogrammed and controlled by digital to analog waveform generators. The Ohmic heating system is capable of providing 125 to $150 \mathrm{~kW}$ to CDX-U. The plasma geometry remains substantially unchanged, with the basic discharge parameters summarized in Table 1.

The CDX-U device also has a radio frequency (RF) heating system that has been upgraded to 250 $\mathrm{kW}$ at the fourth harmonic of the hydrogen ion cyclotron frequency. This will permit parallel and normal heat fluxes will be $5-10 \mathrm{MW} / \mathrm{m}^{2}$ and $1-3 \mathrm{MW} / \mathrm{m}^{2}$, respectively, because of the compact ST geometry. Previously, increases in the central electron temperature of up to $50 \%$ were observed in CDX-U, with $100 \mathrm{~kW}$ of RF power. ${ }^{5}$ The new RF system extends the total heating capabilities to twice the Ohmic power input.

\section{Liquid Lithium Experiments in CDX-U}

The first investigations on the interaction of a spherical torus (ST) plasma with liquid lithium will be performed using a toroidally-local liquid lithium rail limiter (L3). This limiter consists of a heated $20 \mathrm{~cm}$ probe head, which can be inserted into the CDX-U plasma chamber (Figure 1). The PISCES $^{6}$ group at the University of California at San Diego (UCSD) has designed and built the 
probe head and drive mechanism, and the CDX-U group at PPPL has responsibility for the vacuum vessel interface.

In addition to providing a low-recycling limiter for CDX-U discharges, the L3 probe head exposures will permit the evaluation of effects that could not be investigated in the PISCES device. These include the dependence of lithium sputtering on ion angle of incidence, the importance of the magnetic sheath on redeposition, and the role of the ion energy distribution function on the loss rate of lithium from the sample. ${ }^{7}$ It would also be easier to measure the recycling properties of hydrogen on a lithium surface with the liquid lithium rail limiter. We can use the $\mathrm{D}_{\alpha}$ line emission from the $\mathrm{L} 3$ probe head in $\mathrm{CDX}-\mathrm{U}$ as an indication of how much recycling occurring there, whereas in PISCES, the deuterium radiation is not localized to the sample.

In late 2000, CDX-U will operate with the large area, liquid lithium belt limiter. This is a fully toroidal limiter, and as shown in Figure 1, it will be placed at the bottom of the vacuum vessel. The primary goal of these investigations will be to produce an ST discharge in which the plasma-wall interaction is dominated by a liquid lithium surface. The effects of operating with lithium walls will be quantified for the first time, greatly reducing the uncertainties of incorporating liquid lithium walls in larger toroidal devices such as Alcator C-Mod or NSTX.

\section{Diagnostics for liquid lithium experiments}

Diagnosis of the effects of a low-recycling limiter target on the CDX-U plasma will utilize the extensive set of CDX-U diagnostics. A particular concern involves surface impurities that may require a temperature beyond the normal $181^{\circ} \mathrm{C}$ melting point of lithium to liquify the solid coatings they can form. This has been observed in previous lithium experiments. ${ }^{2,8,9}$ The lithium temperature will be varied by heaters on the toroidal limiter container up to $500^{\circ} \mathrm{C}$ to address this issue, and the influx of lithium as it evaporates needs to be monitored spectroscopically as a function of target temperature.

The most basic spectroscopic diagnostic on CDX-U is a monitor of the neutral lithium line emission at $670.8 \mathrm{~nm}$. A filterscope system is being installed to monitor $\mathrm{D}_{\alpha}$ and impurity lines local to lithium limiters. For the L3 experiments, it will use the port immediately below the limiter assembly shown in Figure 1. Additional spectroscopic diagnostics include a Czerny-Terner $0.3 \mathrm{~m}$ monochromator, a far ultraviolet monochromator covering a spectral range from $130 \mathrm{~nm}$ to 250 
$\mathrm{nm}$, and a grazing incidence extreme ultraviolet spectrometer (STRS) which measures between 2 and $36 \mathrm{~nm}$.

Deuterium fueling efficiency and lithium impurity accumulation will also be investigated with the spectroscopic diagnostics on CDX-U. A multi-layer mirror (MLM) array ${ }^{10}$ will observe the 13.5 nm LiIII line for core lithium concentrations. The ten channels of this system are oriented to view across a poloidal cross section of the plasma. With mirrors chosen for measuring the $15 \mathrm{~nm}$ OVI emission, this diagnostic has already been used to observe impurity accumulation in CDX-U discharges.

There is also a ten-channel bolometer ${ }^{10}$ located in the horizontal midplane of CDX-U for a tangential view of the plasma. It can operate either in bolometric mode with unfiltered diodes for total radiated power profiles, or in a configuration that permits OVI or CV emissivity measurements with $250 \mathrm{~nm}$ beryllium or $300 \mathrm{~nm}$ titanium filters. Measurements of CDX-U discharges to date with this array show strong peaking in the radiation losses.

A major new profile diagnostic is the multipoint Thomson scattering (TS) system. ${ }^{11}$ It uses a 5joule ruby laser that passes twice through the plasma along a vertical chord. The scattered photons are collected in twelve channels that provide a spatial resolution of about $2.5 \mathrm{~cm}$. Since the optical table is movable, two-dimensional scanning is possible to obtain almost $70 \%$ of the radial extent of the plasma. Since the TS measurements have difficulties with low signal levels near the plasma edge, they will be augmented in this region by profiles from a new eight-tip "rake" Langmuir probe.

The width of the toroidal belt limiter (Figure 1) was minimized to reduce the lithium inventory and retain the coverage of the plasma with the TS diagnostic. This requires improved plasma position control, and new computer system is being installed for this purpose. Analyses of CDX-U equilibria indicate that more flux loops are needed for both equilibrium reconstruction and plasma control, and they will be added when the machine is vented for the installation of the toroidal belt limiter later in 2000.

A fast visible camera, which obtains 10,000 frames per second, will be used to image the plasma through the tangential port shown in Figure 2. Variations in the surface temperature of the lithium will be observed with an infrared camera. A zinc selenide window will be mounted on a port that has a view of the L3, and there will be a similar arrangement for the toroidal belt limiter. 
A lithium acetylide micropellet injector provides further capability for testing lithium diagnostics and investigating lithium transport in CDX-U. The system uses the mechanism developed for the boron low velocity micropellet injector, ${ }^{12}$ and is capable of delivering particles in the range of 100 to 1000 microns in diameter. The lithium acetylide is loaded into sixteen barrels in a revolving turret, and it is propelled with deuterium at a pressure of 40 PSI. Injection occurs once per discharge, with the smaller particles arriving first at the plasma edge to dissociate, ionize, and be transported to the core.

Coupons mounted on the vacuum side of the walls in fusion devices are an effective and economical means of determining the cumulative effects of the interactions of plasmas with surfaces exposed to them. ${ }^{13}$ Such samples are typically removed at a time when the machine is vented for maintenance and upgrade activities. With experiments involving lithium, the inside of the vacuum vessel is expected to have a coating which must be "passivated" before such work can occur. This process, which involves exposure to air and the removal of the lithium compounds with a solvent, would clearly make any meaningful analysis of the coupons impossible.

A simple solution is to mount the coupons in an airtight enclosure behind a series of gate valves, so they can be removed without venting the vacuum vessel and exposure to atmosphere. This approach has been used successfully with the DIMES probe on DIII-D,${ }^{14}$ where the tip was removed from the machine and shipped for offsite analysis without significant degradation of its surface. Because the technique does not require bringing the entire machine up to air, it has the added advantage of enabling comparisons between coupon exposures of varying durations.

\section{Acknowledgments}

This work was supported by USDOE Contract No. DE-AC02-76-CHO3073. 


\section{References}

${ }^{1}$ M. A. Abdou et al., APEX Interim Report, UCLA-ENG-99-206/UCLA-FNT-107 (1999)

${ }^{2}$ D. K. Mansfield et al., Phys. Plasmas 3, 1892 (1996)

${ }^{3}$ R. Kaita et al., Proceedings of the 18th IEEE/NPSS Symposium on Fusion Engineering, 127 (1999)

${ }^{4}$ J. Menard et al., Physics of Plasmas 6, 2002 (1999)

${ }^{5}$ D. Stutman et al., Plasma Phys. Contr. Fusion 41, 867 (1999)

${ }^{6}$ Y. Hirooka et al., J. Vac. Sci. Technol. A8, 1790 (1990)

${ }^{7}$ N. V. Antonov et al., J. Nucl. Mater. 241-243, 1190 (1997)

${ }^{8} \mathrm{H}$. W. Kugel et al., Proceedings of the 17th IEEE/NPSS Symposium on Fusion Engineering, San Diego, CA, October 6-10, 1997, 869 (1998)

${ }^{9}$ G. Labik et al., Proceedings of the 17th IEEE/NPSS Symposium on Fusion Engineering, San Diego, CA, October 6-10, 1997, 873 (1998)

${ }^{10} \mathrm{~V}$. Soukhanovskii et al., Proceedings of the $13^{\text {th }}$ Topical Conference on High Temperature

Plasma Diagnostics, Tuscon, AZ, June 18-22, 2000

${ }^{11}$ T. Munsat et al., Rev. Sci Instrum. 70, 755 (1999)

${ }^{12}$ H. Kugel et al., Rev. Sci Instrum. 70, 493 (1999)

${ }^{13}$ W. R. Wampler et al.,j. Vac. Sci. Tech. A6, 2111 (1988)

${ }^{14}$ J. N. Brooks et al., "DiMES Divertor Erosion Experiments on DIII-D," SAND96-1281C (1996) 


\begin{tabular}{|c|c|}
\hline Major Radius $\left(\mathrm{R}_{0}\right)$ & $34 \mathrm{~cm}$ \\
\hline Minor Radius $(\mathrm{a})$ & $22 \mathrm{~cm}$ \\
\hline Aspect Ratio $\left(\mathrm{R}_{0} / \mathrm{a}\right)$ & $\geq 1.5$ \\
\hline Elongation $(\kappa)$ & $\leq 1.6$ \\
\hline Triangularity $(\delta)$ & $>0.2$ \\
\hline Toroidal Field $\left(\mathrm{B}_{\mathrm{t}}\right)$ & 0.23 Tesla \\
\hline Ohmic Current $\left(\mathrm{I}_{\mathrm{p}}\right)$ & $\leq 80 \mathrm{kA}$ \\
\hline $\begin{array}{c}\mathrm{P}_{\text {auxiliary }}(\text { radio } \\
\text { frequency heating })\end{array}$ & $\leq 250 \mathrm{~kW}$ \\
\hline
\end{tabular}

Table 1. CDX-U parameters. 


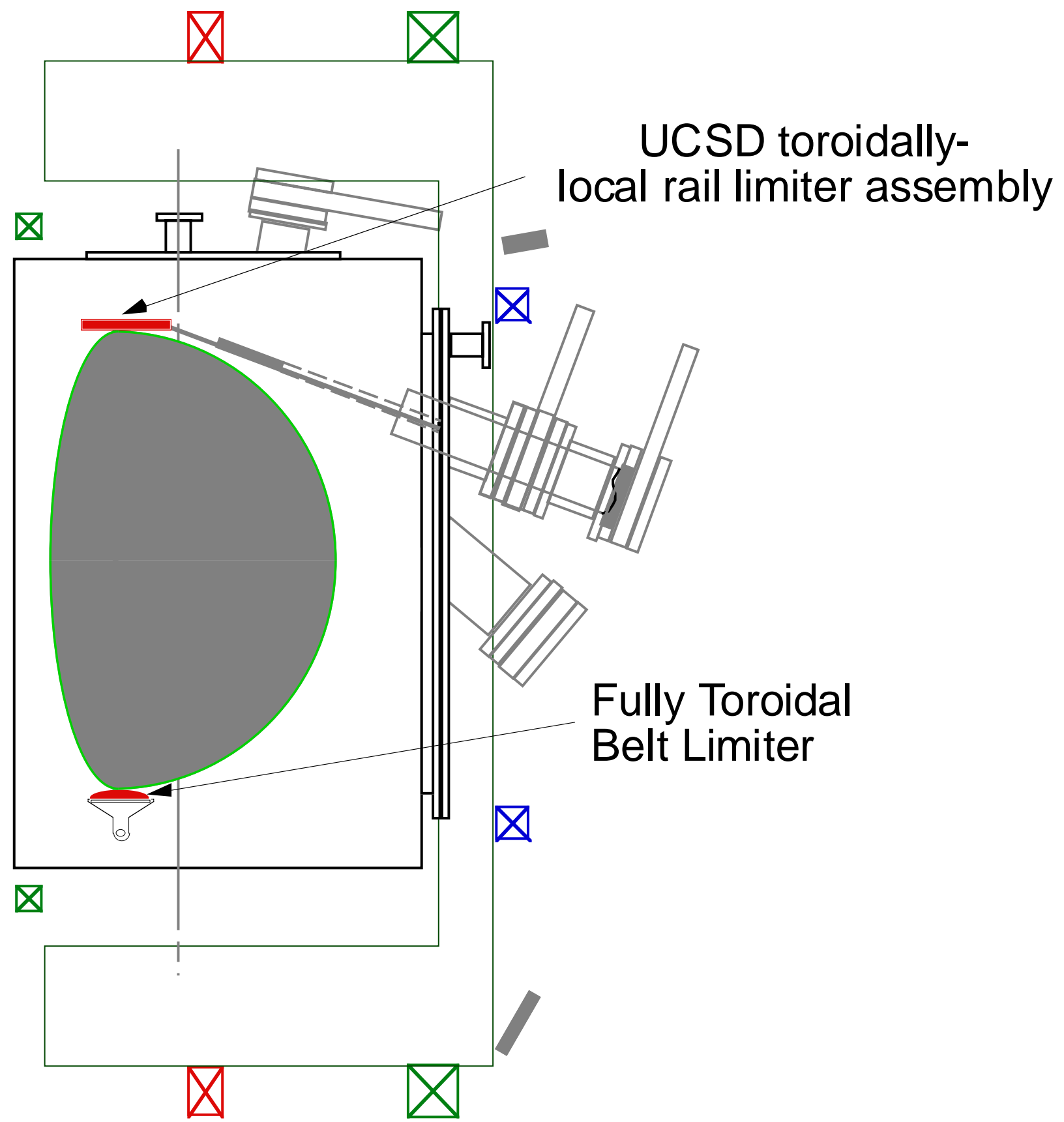

Figure 1. Schematic of CDX-U showing positions of liquid lithium rail limiter (L3) and toroidal liquid lithium belt limiter. 


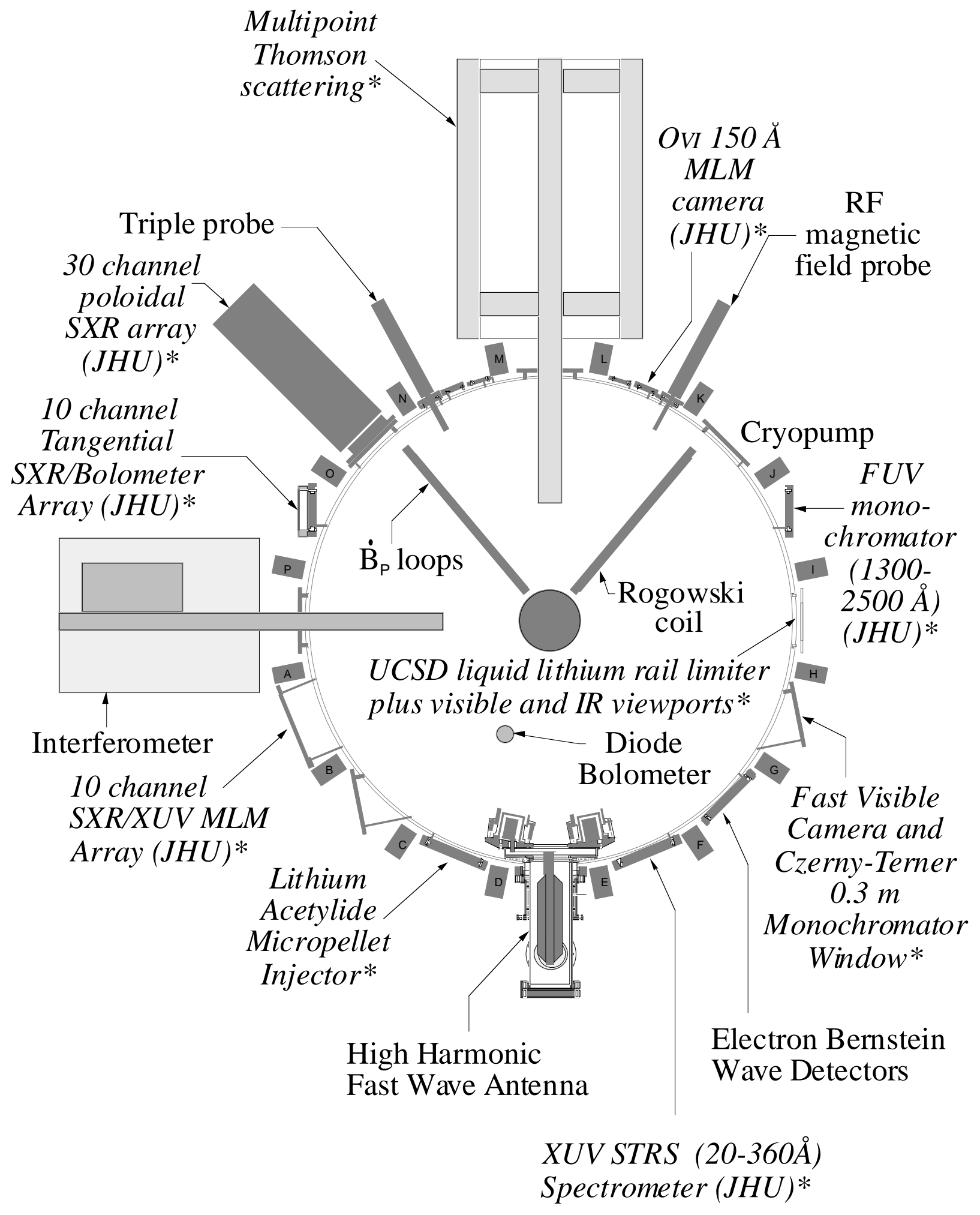

Figure 2. Layout of diagnostics on CDX-U. Diagnostics particularly relevant to liquid lithium experiments are italicized. 
The Princeton Plasma Physics Laboratory is operated by Princeton University under contract with the U.S. Department of Energy.

\author{
Information Services \\ Princeton Plasma Physics Laboratory \\ P.O. Box 451 \\ Princeton, NJ 08543
}

Phone: 609-243-2750

Fax: 609-243-2751

e-mail: pppl_info@pppl.gov

Internet Address: http://www.pppl.gov 